\title{
MAESTRAS DEL PINCEL: \\ MIRADAS VIOLETA ACOMPAÑANDO UN RECORRIDO IMPRESCINDIBLE
}

\author{
MASTERS OF THE BRUSH:
}

AN ESSENTIAL JOURNEY SEEN THROUGH THE PURPLE GAZE

\author{
Carmen Senabre Llabata \\ Colectivo Aula Violeta
}

\section{RESUMEN}

«Maestras del pincel», es el título de una exposición planteada con el propósito de llevar la presencia y la creatividad de las mujeres a espacios no vinculados de manera específica con el mundo del arte, tomando como referencia principal a pintoras del siglo XIX. Sus impulsoras, invitamos a reflexionar sobre las razones de una exclusión injustificable: la Historia del Arte escrita, como cualquier otra, desde una perspectiva androcéntrica, obvió sus nombres y sus obras de forma deliberada; en caso de mencionarlas, al juicio estético le precedía el referido a sus cualidades morales y/o la extrañeza que causaba la calidad artística de un ser escasamente capacitado en tal sentido. El momento actual finge haber normalizado la situación $y$, sin embargo, en pleno siglo XXI, son muchas las facetas en las que hay que continuar reivindicando la igualdad real, en cualquier ámbito de actuación humana.

Palabras clave: feminismo, pintoras, discriminación, género, igualdad.

\section{ABSTRACT}

«Masters of the brush», that is the name given to this exhibition, whose purpose is to introduce the presence and creativity of women in spaces not specifically related to the art world, relying on women painters of the XIX century as the main reference. We invite the public to reflect about the reason behind an unjustifiable exclusion: History of Art, like most academic disciplines, has always been written from an androcentric perspective, and has, as a result, deliberately omitted the names and works of these women. Moreover, if by chance were they ever mentioned in the past, it was just to focus on their moral standing, or to express bewilderment in front of their evident artistic quality, something at the time thought beyond the capacity of «beings so ill-equipped for artistic endeavours»; aesthetic judgement was never a priority. In the present we feign to have normalized this situation, when the truth is still today, in the $\mathrm{XXI}$ century, there is much left to fight for in the pursuit of true equality in every aspect of human activity. Keywords: Feminism, Women Painters, Discrimination, Gender, Equality. 
SUMARIO

1.- Despejando dudas. 2.- Tomar la palabra, esa es la cuestión. 3.- Del autorretrato a la crítica social: un desafío al confinamiento en la esfera privada. 4.- Emancipación versus sumisión. 5.- En construcción.

NO ES NO (a propósito de una sentencia vergonzante e injusta, 26 abril, 2018)

\section{Despejando dudas}

Somos Aula Violeta, un grupo de mujeres que desde hace años se ocupa de acercar el arte de mujeres a través de una mirada feminista. Nuestro trabajo nace del deseo de compartir, de aportar experiencias e ideas al (re)conocimiento de artistas ignoradas 0 reducidas a mera anécdota -es decir, ninguneadas- por la historia del arte. Por ello nos planteamos escribir sobre mujeres que, no hace tanto tiempo, expresaron con sus lienzos, entre otras cosas, emociones e inquietudes propias, pero nunca ajenas al conjunto de la sociedad. Escribir sobre ellas y aproximar sus obras al gran público.

Las diferentes propuestas sobre el momento a estudiar nos condujeron hacia el siglo XIX confluyendo en la necesidad de «exponerlas», volverlas a la vida y destacar la plenitud de su dedicación a la actividad artística; una investigación que derivó, como otras muchas, hacia la necesidad de reclamar su legado y sus nombres a través de sucesivas exposiciones temporales, comenzando por pintoras de aquella época. «Maestras del Pincel», titulamos estas muestras de carácter didáctico, que abordan el período comprendido entre el neoclasicismo y las corrientes impresionistas, con algunas obras pertenecientes al primer tercio del XX.

Las mujeres de esta época son las protagonistas de una muestra pictórica comprometida asimismo con el presente: cuanto más conozcamos a las creadoras que nos precedieron, de su esfuerzo por hacerse un hueco en un mundo dominado por hombres, autoras de telas que delatan su «maestría» y su tesón, mejor comprenderemos que estas mujeres valerosas -como tantas otras anónimas para siempre- derribaron fronteras sexistas y discriminatorias, abriendo senderos que allanaban el camino a cuantas se aventurarían por ellos.

De etapas históricas precedentes, pero en especial a partir del Renacimiento, contamos con pintoras que lograron abrirse paso en el campo del arte, reconocidas entre sus contemporáneos e independientes económicamente como para vivir de su propio trabajo, pese a resistencias y dudas constantes sobre su autoría, su competencia e incluso, su derecho a presentarse en un lugar ajeno, por definición, a sus obligaciones e intereses vitales: no es extraño que ya Vasari -por citar a uno de los primeros biógrafos de artistas- en Las Vidas (1550, segunda edición ampliada y revisada, 1568) construyera un relato a medida de los 
intereses masculinos, en absoluto convincente. Tal vez se convirtiera en libro de cabecera para posteriores estudiosos, a tenor de su insistencia en destacar cualidades morales en las féminas y el afán por atribuir sus cuadros a artistas hombres, cuya cotización al alza estaba garantizada -sólo por el hecho de ser varones- prescindiendo de análisis que corroboraban lo contrario.

Cierto que conforme se fueron articulando los discursos en torno a sexo y género, iban apareciendo investigaciones relativas al tema y proyectos expositivos interesados en destacar -tal vez por su carácter exótico, novedoso y vendible- la aportación femenina en el ámbito artístico, coincidiendo no por casualidad con la apertura cultural a «la otredad», encarnada también por el arte africano o el arte negro tan aplaudidos por críticos de arte y galeristas, a partir de los años noventa del siglo pasado.

Sabiendo pues que el feminismo mantiene ya largo tiempo, una actividad teóricopráctica constante e impagable desde cualquier área de trabajo o de estudio -incluida la vertiente artística- nosotras optamos por dotar a esta exposición viajera de ciertas singularidades, haciendo caso omiso al empeño continuado de aconsejar silencio y discreción a cualquier mujer que se aventure a discrepar y persista en adueñarse de su propia individualidad.

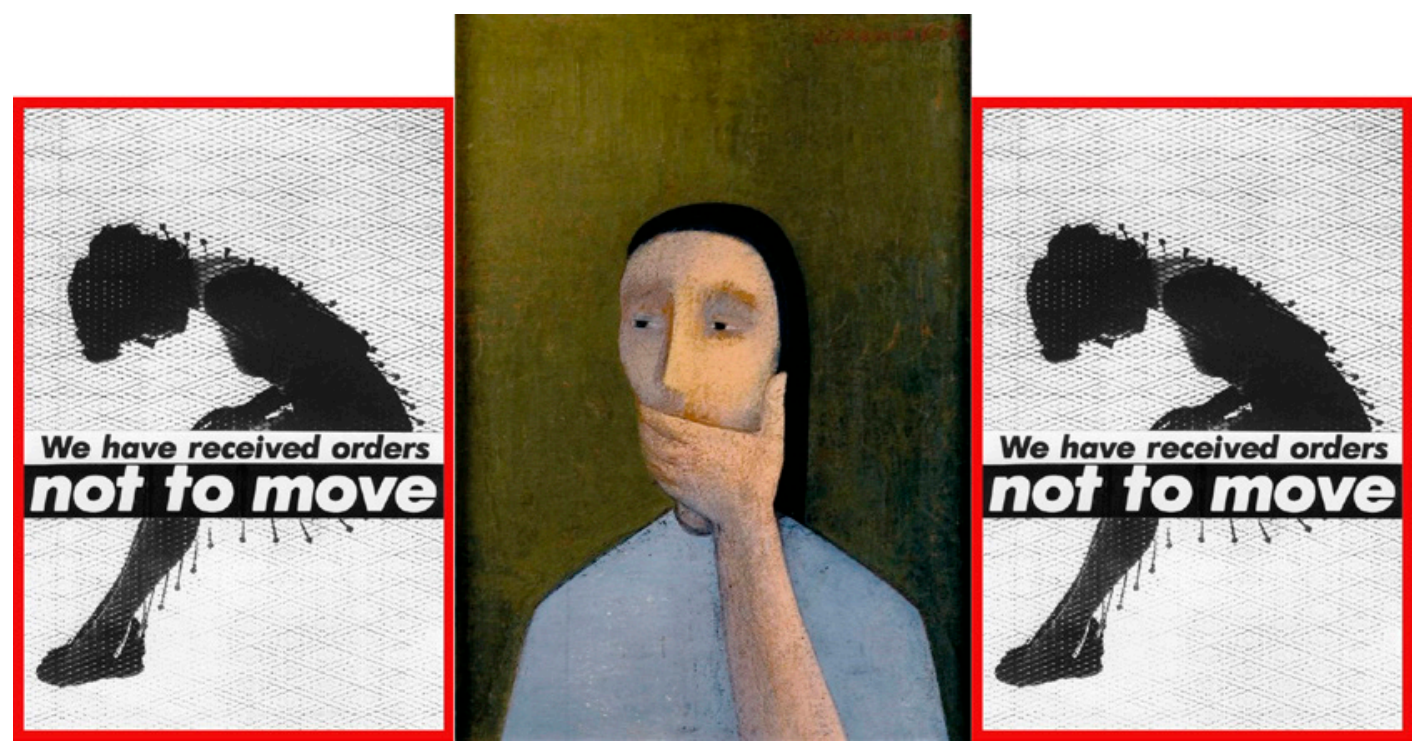

Juana Francés, Silencio, 1953 (en el centro), entre las imágenes de Barbara Kruger, Hemos recibido órdenes de no movernos, 1982. 
«Hemos recibido órdenes de no movernos» (1982), aclaraba Barbara Kruger, conocida artista de los años 70 dispuesta a plantar cara y denunciar con sus obras -mediante la imagen y la palabra- todo tipo de violencia contra las mujeres; ahora mismo el mandato sigue vigente, cuando perviven los prejuicios machistas que -como advierte la historiadora Mary Beard, autora del reciente Mujeres y poder. Un manifiesto (2017) se remontan a la cultura antigua, cuyos textos literarios o filosóficos dan testimonio constante de ello: el destino de las Amazonas siempre marcado por la derrota, Lucrecia, después de ser violada no tuvo otro remedio que suicidarse, Medusa denuncia a Poseidón, su violador y Atenea la castiga convirtiendo su cabellera en serpientes, para acabar decapitada por Perseo, Penélope reprendida y conminada por su hijo Telémaco a regresar a sus aposentos, «porque yo soy el que tiene el poder en este hogar» ¿ Y qué podemos pensar de Hesíodo, Aristóteles o Aristófanes, por ejemplo? ... la sombra del patriarcado es alargada, perturbadora: todas somos Pandora, Lilith o Eva. Una frase tan célebre como «el mejor adorno de la mujer es el silencio» o la sentencia según la cual, "a las mujeres hay que atarlas corto», mutan en el lenguaje cotidiano hacia versiones descarnadas como «tú, cierra el pico», "cállate, zorra» y lindezas similares. A todo ello hay que responder alto y claro, reaccionar frente a cualquier atisbo de agresión -basada siempre en relaciones asimétricas- que niega derechos elementales a buena parte de la humanidad.

\section{Tomar la palabra, esa es la cuestión}

Así pues, abordamos el texto, contando con la experiencia deparada por esta muestra itinerante la cuál -tal como señala el catálogo que la viene acompañando desde su presentación- apuesta por cumplir dos funciones más allá de la puramente estética: una didáctica y otra divulgativa, presentadas mediante paneles informativos, reproducción de obras, datos biográficos y textos sobre sus creaciones. Desde su primera inauguración el año 2013 en el Colegio de Médicos de Valencia, ha recorrido institutos de secundaria -con charlas y trabajos en los que se ha implicado directamente el alumnado- casas de cultura $o$ ayuntamientos de diferentes poblaciones y tiene ya previstas o cerradas fechas para próximas exposiciones; otra de sus características: la apertura a nuevas incorporaciones de artistas, conforme vamos «descubriendo» la existencia de tanto espíritu rebelde en forma femenina.

Este tipo de planteamientos, abre múltiples posibilidades en cada ocasión: lectura de poemas escritos por mujeres -desde Rosalía de Castro a Gioconda Belli- con la idea de subvertir esencialismos identitarios y hacer frente a los tópicos del amor romántico, basados en la dominación masculina, intercalando diversos fragmentos musicales, interpretados a capela o acompañados de una pianista. 
Respecto al fondo del asunto, subrayar de nuevo que desde tiempo inmemorial salvo excepciones ocasionales y conocidas- las mujeres han estado ausentes de los espacios públicos, no por deseo propio sino por imposición, es decir, forzadas a ello por una sociedad patriarcal y misógina, que las condenaba al silenciamiento absoluto. Sin embargo, pese a circunstancias tan desfavorables, muchas de ellas fueron despertando en el siglo XIX y comenzaron a hacer realidad sus sueños de libertad: nació el movimiento feminista al abrigo de las ideas ilustradas y el sufragismo, una marea imparable reivindicando derechos, como el del voto o el de estudiar y, por descontado, el dedicarse a la creación artística. En 1899, aparecería una novela titulada, precisamente, El despertar de Kate Chopin, cuya protagonista encarna esa desazón ante una realidad coercitiva, marcada desde fuera, que la constriñe a ejercer de «ángel del hogar» y su convicción de que, rompiendo las cadenas en un mundo hostil a la emancipación femenina, le esperan grandes ocasiones.

\section{Del autorretrato a la crítica social: desdeñando el confinamiento a la esfera privada}

Esta muestra, dedicada a pintoras con nombre propio -y otras muchas por explorarconstituye una especie de tributo $u$ homenaje a quiénes lucharon con los pinceles para decir basta ya a siglos de discriminación, abriendo puertas para que disfrutaran del sol y el aire -también de los días tormentosos- las generaciones posteriores, en términos de igualdad.

Difundir el trabajo de estas pioneras no es cuestión baladí, ni tampoco un intento de desempolvar viejos agravios comparativos, sino expresión del deseo de contemplar con otros ojos el devenir humano, conforme vayamos recorriendo las imágenes que ofrecen a nuestra mirada: autorretratos, escenas cotidianas o paisajes, pero también críticas a la guerra, la pobreza y la injusticia.

En bastantes de sus composiciones abandonan temas, formatos y técnicas considerados propios de la condición femenina, sin eludir el coste social que ello podría suponer. Los críticos de arte de la época no salían de su asombro, aunque algunos supieron rectificar «yo siempre decía que ninguna mujer podría pintar»-acabaría reconociendo Ruskin, ante la obra de Elisabeth Thompson- cuando la verdad es que no existe relación alguna entre la habilidad para manejarse con los pinceles -cuestión que nos ocupa-y los cromosomas.

Recobrarlas no pasa simplemente por ampliar el catálogo de celebridades, sino por revisar los supuestos valores que el canon artístico occidental ha ido trazando para otorgar credenciales e índices de creatividad, partiendo siempre de un punto de vista androcéntrico. Es posible que la ruptura con lo artísticamente correcto no aparezca de manera explícita o provocadora, pero las posteriores investigaciones desde la perspectiva de género, nos hablan de ese feminismo velado e íntimo que podemos advertir en artistas alejadas en el tiempo. 
Es, cuanto menos, llamativo que la mayoría de ellas cayera en el olvido, porque cumplían los requisitos exigidos para triunfar: habían logrado fama y éxito incluso fuera de sus lugares de origen, vendían muy bien sus cuadros y participaron en numerosas exposiciones -individuales 0 colectivas- por diferentes países; también es cierto que gozaban de un estatus social relativamente alto y compartían una educación similar a la de sus hermanos varones que favorecía la formación artística, no siempre alentada desde el entorno familiar. Y, por último, practicaban una especie de feminismo vital, sobreentendido irónicamente, apenas insinuado con temas de interior o domésticos en sentido estricto, como sucede con Pelando cebolla (1852), de Lilly Martin Spencer (1822-1902).

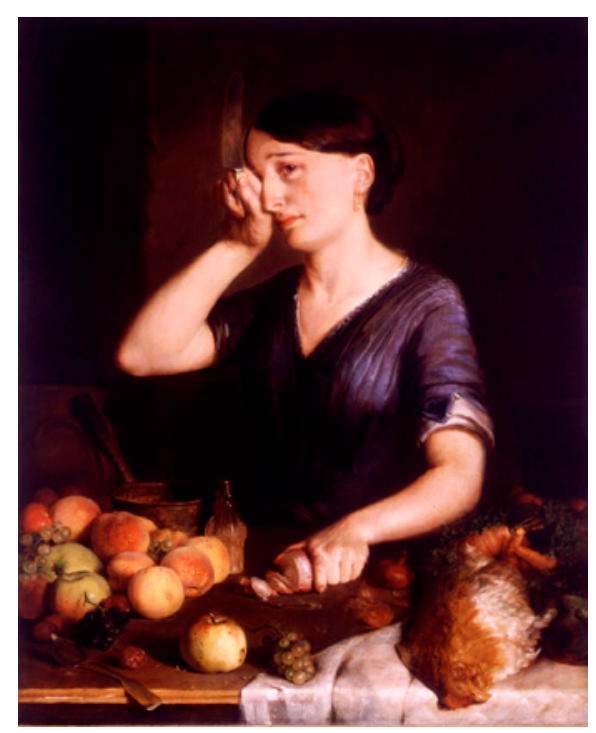

Lilly Martin Spencer, Pelando cebolla, 1852.

O argumentos inéditos e inaceptables para abordarlos una mujer, como sucede con Rosa Bonheur (1822-1899), abiertamente homosexual, cuya aportación más celebrada fue Feria de caballos, (1853), desafiando tabúes tanto en su vida personal como en el terreno artístico; y un tercer ejemplo del realismo -siempre entendido de modo muy amplio- lo encontramos en la citada Elizabeth Thompson (1846-1933) que, también contra la tradición artística establecida para la pintura femenina, alcanzó gran notoriedad con obras de gran formato y un verismo extraordinario, plasmando sin ambages los horrores de cualquier guerra: en Pasando lista tras el combate (1874) - El $28^{\circ}$ regimiento en Quatre Bras (1875) quedan reflejados de tal modo, que casi nos obliga a enmudecer. 


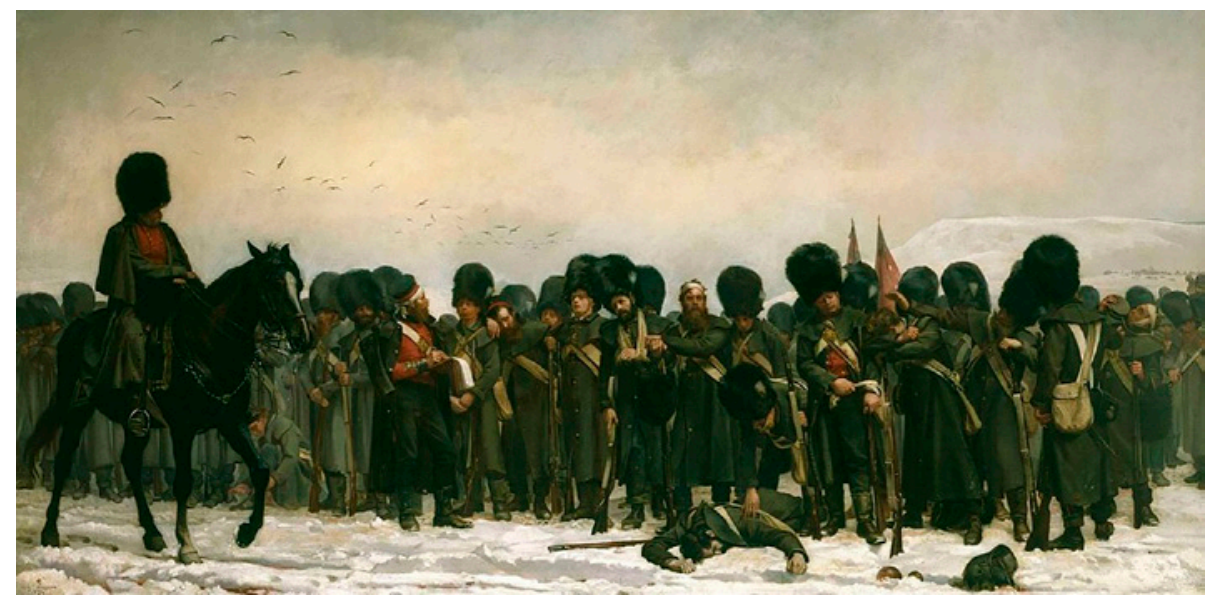

Elizabeth Thompson, Pasando lista tras el combate, 1874.

Corrían vientos de rebeldía. Pese a vetos y restricciones para moverse con libertad, sus creaciones evolucionan al compás del arte de su tiempo, sin embargo, la persistencia de asuntos domésticos (propios de la feminidad) podría interpretarse como total asunción del papel heterodesignado y esencialista adjudicado a las mujeres desde siempre: el ángel del hogar comenzaba a dejar de serlo.

Contemplar con otra mirada, más allá de técnicas y estilos compartidos con sus homólogos masculinos, permite entrever en esas representaciones de la vida cotidiana -leyendo, abrazando a una criatura, tendiendo la ropa, lavándose semidesnuda, jugando a cartas y fumando, pintando en su estudio o relajándose en la playa- un poso de tristeza, de cansancio, difíciles de explicar. Además, en un contexto adverso, pero también empeñado en transformarse, algunas de ellas no dudaron en sumarse pública y activamente a los movimientos sociales de la época, tales fueron los casos por ejemplo de Barbara Bodichon (1827-1891) -con una formación multidisplinar- o Emily Mary Osborn, (1834-1925) autora de Sin fama ni amistades (1857) un cuadro revelador y pertenecientes ambas a la Langhem Place Circle, que luchaba por los derechos de las mujeres. 


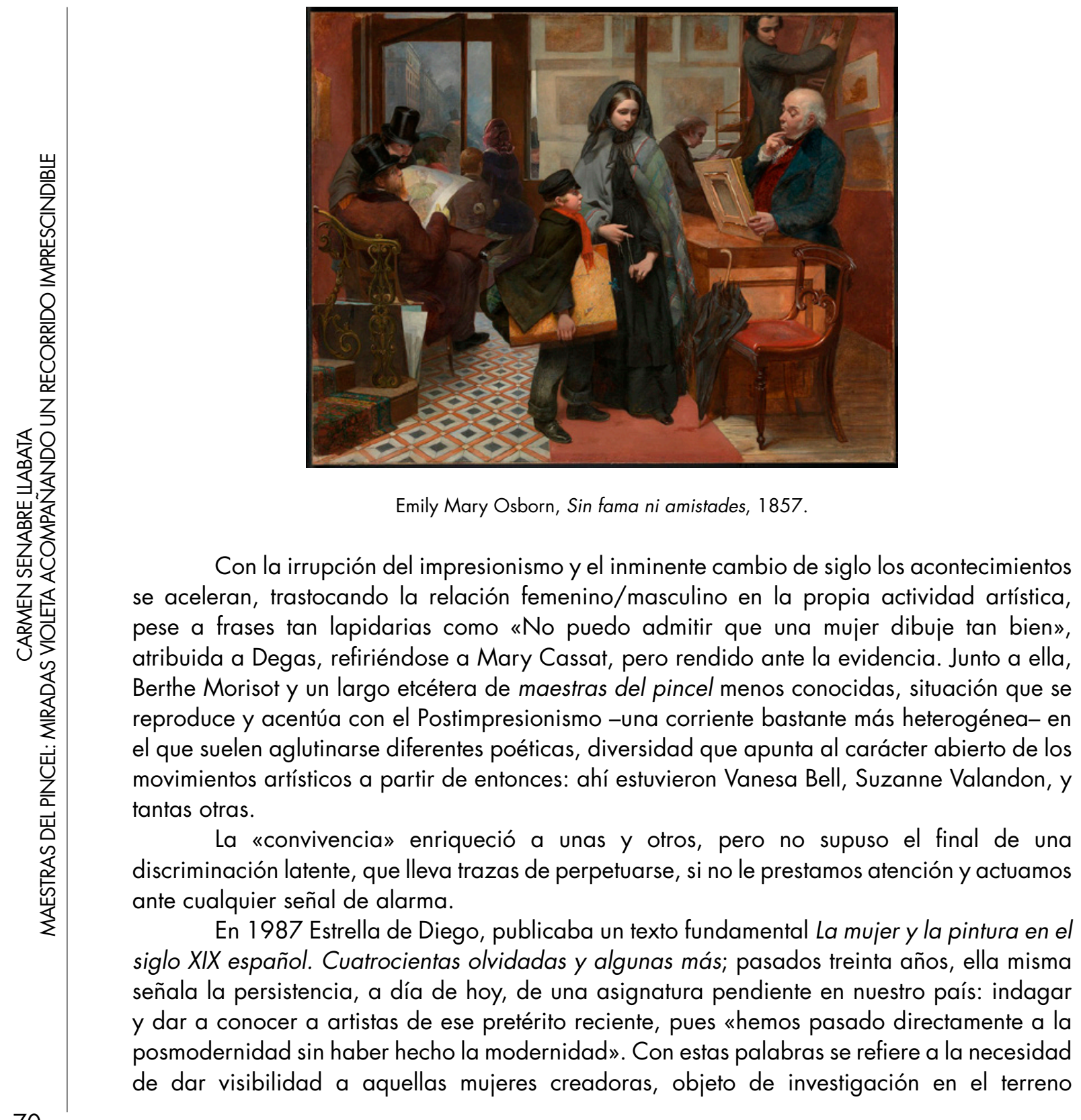


académico -con un despliegue importante de estudios feministas, desde hace décadas- pero escasa presencia en museos y galerías de arte: «Frente a lo que ha pasado en otros países de nuestro ámbito, esa primera y elemental fase de reconstruir la historia, recuperar a las artistas y las imágenes locales no se ha llevado nunca a cabo de manera sistemática» subraya.

Algunas iniciativas recientes al respecto: De objeto a sujeto: género $y$ arte en Alicante desde el siglo XIX, del colectivo Género y Cultura Visual cuya propuesta -revisitar la colección permanente del MUBAG referida a dicho período- reivindica en esta ocasión a artistas alicantinas apenas representadas, y amplía el debate en torno al patriarcalismo en la sociedad decimonónica, así como su pervivencia en la actualidad.

Otra aproximación a creadoras e imágenes «locales»: A contratiempo: medio siglo de artistas valencianas (1929-1980), presentada en el IVAM, un recorrido alrededor de momentos históricos clave para entender el presente, contado a través de lienzos que traen a la luz, una vez más, las dificultades de las mujeres para hacerse ver/oír, discriminadas por partida doble en cualquier circunstancia.

Un simple rastreo genealógico revela que el discurrir del arte y de la cultura en general así como las sucesivas revoluciones tecnológicas, no han constituido en sí mismos avances significativos para el conjunto de la sociedad; en paralelo, nos permite observar que la resignación y la pasividad -impuestas o aceptadas- encubren relaciones de dominación incompatibles con la libertad. Desde una perspectiva feminista, el fin de siècle, decimonónico sería un ejemplo claro de tales contradicciones: los progresos científicos, corroboraban la inferioridad intelectual de las mujeres, cuya participación en la esfera pública comprometería la evolución y el progreso del hombre (comprendiendo aquí sí, exclusivamente a los varones de la especie humana); de este modo se cerraba el círculo: si los padres de la iglesia católica habían aseverado que las mujeres no tienen alma, el cientifismo decimonónico-acompañado por escritores, artistas e intelectuales de la época- decidía que no tenían cerebro, incapaces de pensar por su cuenta en definitiva, «ídolos de perversidad» siempre dispuestos a exhibir y satisfacer sus afanes libidinosos.

\section{Emancipación versus sumisión}

Cuando ellas/nosotras deciden tomar impulso, convirtiéndose en sujeto y objeto de la experiencia estética, las intocables representaciones de la feminidad acaban saltando por los aires: adiós a maternidades felices (amamantando a un niño y/o rodeada de unos cuántos), vírgenes, santas extasiadas, mujeres en actitud recogida, cosiendo o leyendo textos piadosos y en el extremo opuesto imágenes de odaliscas, prostitutas, brujas malvadas... malas malísimas. En fin, todo un repertorio al gusto/servicio de las fantasías masculinas. 
Tanto en retratos como autorretratos las maestras del pincel ya tomaron distancia frente a dicho planteamiento dicotómico y absurdo, que en el arte actual desafía sin complejos los cánones establecidos e incluso la propia noción de canon: relatos sobre la «feminidad», en absoluto complacientes ni convencionales, con una mirada dispuesta a desvelar secretos y mentiras sobre la identidad, la asignación de roles o la dualidad público/privado.

Una de las claves está precisamente en la posibilidad de compartir esa visión transgresora, atenta a derribar las estructuras piramidales presentes en cualquier espacio de la sociedad; ya no se trata de reclamar una presencia equilibrada en el venerado mundo del arte $-y$ toda la parafernalia que gira a su alrededor- sino de cuestionar además su funcionamiento: tipo de exposiciones, criterios de selección en los proyectos presentados, presupuestos exagerados, dirección de instituciones museísticas, comisariados sin concurso público o amañados, ferias de arte contemporáneo, subastas y demás; tampoco es suficiente con hacer añicos el imperceptible techo de cristal, ni con abandonar el claustro como metáfora: para comenzar la tarea, habrá que hacer tabula rasa, si es preciso, de valores estéticos presuntamente universales e inamovibles

La video-fotógrafa Cristina Lucas asegura con sarcasmo, "Tú también puedes caminar» (2006) -como ya había manifestado Virginia Woolf en Una habitación propia (1929)- respondiendo ambas a críticos de todo pelaje capaces de comparar a compositoras, bailarinas o cualquier otra actividad pública llevada a cabo por una mujer, con un perro que «anda sobre sus patas traseras. No lo hace bien, pero ya sorprende que pueda hacerlo en absoluto».

Es posible que de ese modo, contribuyamos al empeño de visibilizar hallazgos artísticos, pensados desde la ruptura con la centralidad (lo masculino) dando paso a los márgenes (no esencialistas), a la transgresión de los límites impuestos por una visión estática del arte y sus aledaños.

En un famoso texto de 1971 titulado «ìPor qué no ha habido grandes mujeres artistas?» Linda Nochlin daba respuesta a ciertos interrogantes, partiendo de una revisión vindicativa de la historia del arte, para destacar la importancia del contexto en que se instaura, señalando a «las estructuras y operaciones que tienden a marginar cierto tipo de producciones artísticas, mientras que centralizan otras».

Ha llovido mucho desde entonces, y las preguntas se fueron ampliando, ¿Por qué no ha habido grandes mujeres pornógrafas?, espetaba Naomi Salaman en 1992, entrando en un tema más polémico si cabe, al que la revista El Viejo Topo había dedicado sendos artículos un par de años antes, comenzando con un tópico recurrente: «La pornografía jes cosa de hombres?». Todo ello, sigue discutiéndose dentro y fuera del ámbito artístico, atendiendo en especial a sus posibles interpretaciones «fraudulentas»; a ese respecto, habrá que recordar 
entre otras, la larga tradición del desnudo femenino en la historia del arte, el oscurantismo que acompañó a su exhibición durante siglos -reservada a ciertos privilegiados-y por supuesto, la delgada línea roja que separa los conceptos de erotismo, obscenidad y pornografía en el ámbito artístico. El libro de Raquel Osborne, La construcción sexual de la realidad, resulta esclarecedor en muchos aspectos teóricos sobre este asunto.

Tomemos un ejemplo de diferentes varas de medir: El origen del mundo (1866), pintado por Courbet en el período histórico que veníamos analizando y cuyos avatares posteriores lo envolvieron en un halo de misterio, que catapultó a su autor a lo más alto. Un lienzo que desafíaba el orden moral vigente, fue recibido con cierto estupor, suscitando respuestas encontradas, incluso en la actualidad, por más que se haya convertido en un «intocable»; mientras para sus detractores no era más que «pornografía pura», «una obscenidad»-sin marcar distinción entre ambas- y negándole precisamente por ello su condición artística, en cambio para otros no sólo estamos ante una obra maestra rupturista sino que además «representa a todas las mujeres» y "constituye la expresión suprema de la feminidad», en palabras de Thierry Savatier en un ensayo donde analiza la tela en cuestión.

A partir del siglo XX las «apropiaciones» han sido una faceta tan recurrente en el quehacer artístico que casi se ha convertido en una expresión más y El origen... no ha escapado a ellas: Valie Export en 1969, Orlan o Marina Abramobic, cada una a su manera respondieron con ironía contenida pero ha sido Deborah de Robertis quien ha llevado más lejos su relectura «exponiendo» en vivo el original con el título, Espejo de origen (2014), en el Museo de Orsay sentada en el suelo bajo la atenta mirada del cuadro del pintor, del público y de los responsables del orden que reaccionaron según su cometido: la performer llevó a cabo la acción sin permiso alguno mientras la gente sorprendida, aplaudía, la grabación en

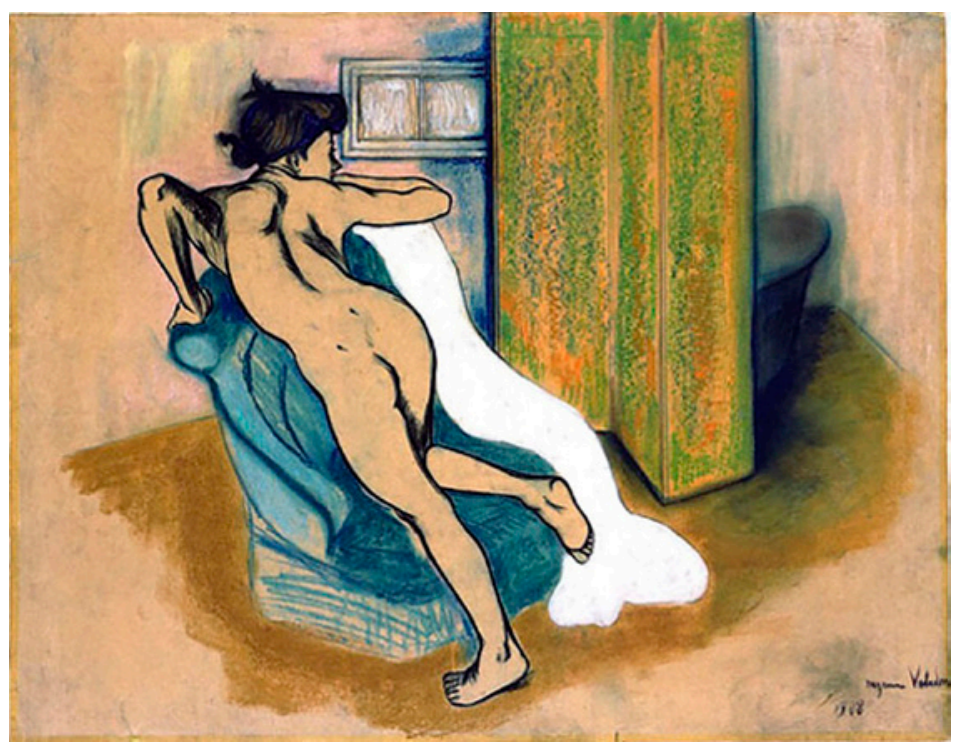

Suzanne Valadon, Después del baño, 1908. 
video era requisada y su paso por las redes eliminado en diversas plataformas. Cada una de sus nuevas intervenciones produce un revuelo similar, pero apenas dan lugar a críticas sobre los límites del arte, sino sobre la libertad de expresión. En 2016, detenida por «exhibicionismo sexual», en otra ocasión interrumpida durante una charla y obligada a abandonar la sala por mostrar fotografías de sus genitales, cuando estaba cuestionando el modo en que se interpreta la desnudez, según la/el protagonista.

\section{En construcción}

Después del esfuerzo por recuperar la memoria y el valor de artistas del pasado -heroínas en tiempos difíciles- vivimos una aparente neutralidad en cuanto al género se refiere, sin embargo, el riesgo de retroceder en todos los sentidos permanece.

Aun así, pensamos -y disculpen la insistencia- que a partir del instante en que las mujeres resuelven convertirse en sujeto y objeto de sus propias creaciones, retratándose a sí mismas sin complejos o apropiándose de temas tabú, la suerte está echada: siguen cualquier dirección no señalizada o donde ponga «prohibido el paso», van a ver qué sucede, qué tratan de ocultar con tanto ahínco, por nuestro propio bien.

Desde Aula Violeta, que ha ido creciendo y consolidándose trabajando junto a otros colectivos feministas, apostamos por celebrar este tipo de encuentros, cuyos debates plurales resultarán quizás lo más enriquecedor de tal intromisión en los espacios artísticos, cuyo uso y disfrute estuvo reservado por mandato divino -en consecuencia, imposible exigir explicaciones- al genio masculino.

Para finalizar, por alusiones:

Jean Jacques Rousseau (1712-1778): «No debéis consentir que no conozcan el freno durante un solo instante de su vida».

Manuel Rivas, 7 enero 2018, A propósito de Órdenes de no movernos: «lo ideal para algunos críticos sería que existiese un feminismo "bien entendido". Es decir, un feminismo no feminista».

\section{Referencias}

Arribas Pérez, Carmelo (2007). Ilustres y desconocidas, Instituto de la Mujer de la Junta de Extremadura.

AAVV, (2013). Maestras del Pincel, Catálogo de la exposición sobre pintoras del siglo XIX, realización y coordinación Aula Violeta, València. 
Bartolena, Simona (2005). «Berte Morissot», en El Impresionismo en detalle, Milán: Electa, pp. 205-223.

Beard, Mary (2018). Mujeres y poder. Un manifiesto, Barcelona: Crítica.

BORNAY, Erika (1990). Las hijas de Lilith, Madrid: Cátedra.

BraY, Xavier; Wilson-Bareau, Juliet y Scot, Bill (2001). Mujeres impresionistas: la otra mirada. Catálogo de exposición, Museo de Bellas Artes de Bilbao, 12 de noviembre de 2001 a 3 de marzo de 2002, Bilbao: Museo de Bellas Artes de Bilbao.

Carro Fernández, Susana (2008). Mujeres de ojos rojos. Del arte feminista al arte femenino, Gijón: Trea.

CAso, Ángeles (2008). Las Olvidadas, una historia de mujeres creadoras, Barcelona: Planeta. CHADWICK, Whitney (1992). Mujer, arte y sociedad, Barcelona: Destino.

Chadwick, Whitney y Courtivron, Isabelle de (1994). Los otros importantes, Madrid: Cátedra. ChopIN, Kate, (2011) El despertar y otros relatos, Barcelona: Alba clásica.

Coll, Isabel (2001). Diccionario de mujeres pintoras en la España del XIX, Barcelona: Centauro.

Combalía, Victoria (2006). Amazonas con pincel: vida y obra de las grandes artistas del siglo $X V I$ al siglo XXI, Barcelona: Destino.

DIEGO, Estrella de (1987). La mujer y la pintura del siglo XIX español (cuatrocientas olvidadas y algunas más), Madrid: Cátedra.

_ (1996). «Figuras de la diferencia», en BozAl, Valeriano (ed.) Historia de las ideas estéticas y de las teorías artísticas contemporáneas (vol. II), Madrid: Visor, pp. 346-363.

DIJKSTRA, Bram (1994). Ídolos de perversidad. La imagen de la mujer en la cultura de fin de siglo, Barcelona: Debate, C. Lectores.

EISENMAN, Stephen 2001). Historia crítica del arte del siglo XIX, Madrid: Akal.

LóPEZ Fernández-CAO, Marian, coord (2000). Creación artística y mujeres: recuperar la memoria, Madrid: Narcea.

Girard, L; Bennefous, M; RudelL, J (1966). «1848-1914», Collection d'Histoire Louis Girard. Paris. Bordás.

HuICl, Fernando y DieGo, Estrella de (1999). Fuera de orden: Mujeres de la Vanguardia española. Catálogo de la exposición celebrada en Madrid, Fundación Cultural. MAPFRE VIDA, del 10 de febrero al 18 de abril. Madrid, MAPFRE.

IBIZA I OsCA, Vicent (2006). Obra de mujeres artistas en los museos españoles, Valencia: Centro Francisco Tomás y Valiente.

MaYAYO, Patricia (2003). Historia de mujeres, historias del arte, Madrid: Cátedra.

Mínguez García, Hortensia (2012). «La mujer en el arte del pasado siglo. Tres visiones, tres mujeres: Mary Cassat, Louise Nevelson y Sonia Delaunay», en H+D HÁBITAT MAS DISEÑO, año 4, núm. 8, pp. 24-29. 
NASH, Mary (1993). Historia de las Mujeres, vol. IV, Madrid: Taurus.

NochuN, Linda (1971) «iPor qué no ha habido grandes mujeres artistas?», artículo publicado por primera vez en Art News.

PORQUERES, Bea (1994). Reconstruir una tradición. Las artistas en el mundo occidental, Madrid: Horas y Horas.

Rocamora, Carmen (2001). "Mujeres pintoras del siglo XX», en Arbor CLXVIII, 321 1-331.

Rosen, Charles \& Zerner, Henri (1988). Romanticismo y Realismo. Los mitos del arte de siglo $X I X$, Madrid: Hermann Blume.

RuBıo Pérez, Isabel (2001). Mujeres que rompieron el estereotipo: las pintoras, Murcia, Comunidad Autónoma de la Región de Murcia, Conserjería de Presidencia, Secretaría Sectorial de la Mujer y de la Juventud.

Savatier, Thierry, (2009) El origen del mundo. Historia de un cuadro de G. Courbet, Gijón: Trea Artes.

TRIVIÑO CABRERO, Laura (2009). De la esfera doméstica al «aire libre»: breve aproximación a las diferencias de género en los y en las artistas impresionistas. En Actas del primer congreso Virtual sobre Historia de las Mujeres, 15-31 de octubre 2009, Cádiz: Universidad de Cádiz. 